\title{
Estimated and Measured BMI and Self-Perceived Body Image of Adolescents in Germany: Part 1 - General Implications for Correcting Prevalence Estimations of Overweight and Obesity
}

\author{
Bärbel-Maria Kurth Ute Ellert \\ Department of Epidemiology and Health Reporting, Robert Koch Institute, Berlin, Germany
}

\section{Keywords}

Adolescent · BMI - Body mass index - Epidemiology · Obesity · Overweight · Body image $\cdot$ Bias

\section{Summary}

Objective: This study examines the degree of divergence between BMI calculated from subjective assessments and $\mathrm{BMI}$ calculated from measured height and weight as a function of gender and body image. Methods: In the German National Health Interview and Examination Survey for Children and Adolescents (KiGGS) the height and weight of 17,641 children and adolescents aged 0-18 years were measured. Participants were also questioned about their subjective body image (whether they considered themselves much too thin, a bit too thin, exactly the right weight, too fat or much too fat). A representative subsample of adolescents between 11 and 17 years old ( $N=3,436$ : 1,663 boys and 1,773 girls) was asked additionally to self-report their body weight and height before being measured. Results: The bias in the self-reported BMI yielded an underestimation of overweight and obesity prevalence. Girls who considered themselves much too fat or too fat and boys who considered themselves as much too fat underestimated their BMI. This was taken into account using a correction procedure for prevalence estimates of overweight and obesity based on the concept of conditional probabilities. Conclusion: The proposed correction formula using data from the KiGGS study can be applied to other German studies of adolescents in which weight, height and body image are only determined by self-report. Furthermore the correction procedure in principle can be transferred to other studies in other countries as long as a parallel validation study has been conducted to assess both subjective and objective BMI and body image.

\section{Introduction}

There is considerable evidence in specialist literature that subjectively determined BMI data shows distortions compared to objectively ascertained BMI data, particularly among adults. All publications on this topic have observed that subjective BMI tends to underestimate objective BMI and that estimates of the prevalence of overweight and obesity consequently tend to be too low. The conclusions drawn from these observations range from a general rejection of determining height and weight by self-report $[1,2]$ to suggesting corrective procedures for subjective BMI $[3,4]$ to recommending the use of subjective data only from certain age and population groups where distortions are lower [5-7]. Furthermore, a European study comparing the correlations between subjective and objective BMI in different European countries concluded that the level of correspondence between the subjective and objective BMI varies from country to country and that no comparable estimates of the prevalence of overweight and obesity can therefore be made on the basis of subjectively collected BMI data [8]. The reasons for these variations may be different cultural backgrounds or perhaps different 'ideals of beauty'. Whichever is the case, national validation studies are necessary.

Results among children and adolescents are analogous to those from adults, although the number of published studies is smaller [9]. The degree of divergence between subjective and objective BMI as a function of age and gender has been de-

\section{KARGER}

Fax +497614520714

Information@Karger.de

www.karger.com
(C) 2010 S. Karger GmbH, Freiburg

Accessible online at:

www.karger.com/ofa 
scribed in different countries. In NHANES III [10] (USA), subjective data on the height and weight of 1,657 adolescents aged between 12 and 16 years were compared with measured data. The degree of BMI underestimation tended to be highest among obese adolescents. Furthermore, girls showed a larger bias than boys.

In the National Longitudinal Study of Adolescents' Health [11] (USA) the subjective height and weight assessments made by 15,483 adolescents aged between 13 and 17 years were compared with objective measurements. There was a high correlation between subjective and objective BMI although the subjective BMI underestimated the objective BMI. A correction of the subjective BMI was recommended in [12]. The proposed correction procedure was developed using the subjectively and objectively assessed BMIs of only 143 pupils in Sienna and does not seem to be generally applicable.

Some studies have shown that boys and girls who felt 'too fat' or wished to be leaner underreported their weight to a greater extent than those who were satisfied with their body size [13, 14]. The Cross National Student Health Survey (CNSHS) [15] consisting of 5,900 records of university students from Bulgaria, Germany, Lithuania, Poland, Spain and Turkey came to the same conclusion.

In the German Health Survey for Children and Adolescents (KiGGS), a random subsample of adolescents between the ages of 11 and 17 years ( $\mathrm{N}=3,473$ : 1,678 boys, 1,795 girls) were asked to report their body weight and height before being measured and weighed at the study center. Comparing self-reports with the subsequent measurements makes it possible to examine the degree of divergence between the two assessment methods. The participants were also questioned about their subjective body image (whether they considered themselves to be much too thin, a bit too thin, exactly the right weight, too fat or much too fat). The aim of this paper is to identify a correction procedure using this additional information.

\section{Material and Methods}

\section{Study Design and Sample}

The aim of the KiGGS study was to collect comprehensive nationwide representative information on the health of children and adolescents aged between 0 and 17 years living in Germany. Participants were enrolled in two steps: First, 167 study locations (sample points) were chosen. Second, subjects were randomly selected from the official registers of local residents. A total of 17,641 children and adolescents were surveyed (8,965 boys and 8,656 girls). Survey participants were given a medical and physical examination, and those over the age of 11 also completed a written questionnaire. In addition, the parents of all participating children and adolescents filled in a questionnaire and took part in a standardized, computer-assisted medical interview. Comprehensive laboratory diagnoses were carried out on the blood and urine samples obtained. The study was approved by the Charité/Universitätsmedizin Berlin ethics committee and the Federal Office for the Protection of Data. Each subject's informed consent was a precondition for all investigations. Details have been published on the study design, including the sampling procedure, the execution and procedure of the study, data management, quality assurance and the inclusion of migrants [16].

\section{Anthropometric Measures}

Standard methods were used at each study location to determine height and weight. Each subject's height was measured, while standing, to an accuracy of $0.1 \mathrm{~cm}$ using a calibrated stadiometer. Weight (in underwear) was determined on calibrated scales to the nearest $0.1 \mathrm{~kg}$.

\section{Objective $B M I$}

BMI was calculated by dividing the measured body weight in $\mathrm{kg}$ by the square of the measured height in meters.

BMI is used internationally to assess population-specific prevalence of overweight and obesity.

Kromeyer-Hauschild's BMI reference values [17] are currently used to define overweight and obesity in children and adolescents in Germany in line with the recommendations of the Study Group on Obesity in Childhood and Adolescence (AGA) (see www.a-g-a.de). The latest evidence from the KiGGS study on the prevalence of overweight and obesity in children and adolescents was determined on the basis of these reference values [18]. According to this, children are considered overweight if they have a BMI above the 90th age- and gender-specific percentile of the reference system of Kromeyer-Hauschild. They are deemed obese if their BMI is above the 97 th percentile. Children or adolescents with a BMI below the age- and gender-specific 10th percentile are defined as underweight; those below the 3rd percentile are considered extremely underweight.

\section{Perceived Obesity / Body Image}

In the KiGGS questionnaire, all 11- to 17 -year-olds $(\mathrm{N}=6,697: 3,426$ boys and 3,271 girls) were asked to report their body image on a five-point Likert-type scale:

'Do you think you are

- much too thin

- a bit too thin

- exactly the right weight

- a bit too fat

- much too fat?'

This instrument was implemented in the international HBSC (Health Behavior in School-Aged Children) study conducted by the WHO [19]. For the KiGGS study, the official German translation was used [20].

\section{Subjective BMI}

When they arrived at the study center, a random selection of boys and girls aged between 11 and 17 years $(\mathrm{N}=3,473$ : 1,678 boys and 1,795 girls, average age 14.7 years) were asked to self-report their height and weight before being measured and weighed.

With the help of these subjective statements on height (height sub $_{\text {}}$ ) and weight ( weight $_{\text {sub }}$ ), a 'subjective' BMI was determined for the subsample.

$$
\mathrm{BMI}_{\text {sub }}=\text { weight }_{\text {sub }} / \text { height }_{\text {sub }}^{2}
$$

\section{Data Analysis}

In the subsequent analyses, in order to characterize deviations between the subjective statements and the objective measurements, the respective differences were defined as follows:

$$
\begin{aligned}
& \text { Diff }(\text { weight })=\text { weight }_{\text {sub }}-\text { weight } \\
& \text { Diff }(\text { height })=\text { height }_{\text {sub }}-\text { height } \\
& \text { Diff }(\mathrm{BMI})=\mathrm{BMI}_{\text {sub }}-\mathrm{BMI}
\end{aligned}
$$

A negative value of these differences indicates a subjective underestimation and a positive value an overestimation of the respective measurement. For these differences descriptive statistics are shown as means and $95 \%$ confidence intervals $(95 \%-\mathrm{CI})$. If the $95 \%$-CI did not include 0 , the 
Table 1. Subjective over- and underestimation of height, weight and BMI by 11- to 17-year-olds as a function of gender and their actual weight category ${ }^{\mathrm{a}}$

\begin{tabular}{|c|c|c|c|c|c|c|}
\hline & \multicolumn{2}{|c|}{ Weight $_{\text {sub }}$ - weight, $\mathrm{cm}$} & \multicolumn{2}{|c|}{ Height $_{\text {sub }}$ - height, kg } & \multicolumn{2}{|c|}{$\mathrm{BMI}_{\mathrm{sub}}-\mathrm{BMI}, \mathrm{kg} / \mathrm{m}^{2}$} \\
\hline & mean & $95 \%-C I$ & mean & $95 \%-\mathrm{CI}$ & mean & $95 \%-\mathrm{CI}$ \\
\hline \multicolumn{7}{|l|}{ All } \\
\hline Boys & $-0.5^{*}$ & -0.8 to -0.3 & $0.2^{*}$ & $0.0-0.4$ & $-0.2^{*}$ & -0.3 to -0.1 \\
\hline Girls & $-0.8^{*}$ & -1.0 to -0.6 & $0.7^{*}$ & $0.5-0.8$ & $-0.5^{*}$ & -0.6 to -0.4 \\
\hline All & -0.7 & -0.8 to -0.5 & 0.4 & $0.3-0.6$ & -0.4 & -0.4 to -0.3 \\
\hline \multicolumn{7}{|c|}{ BMI $\varepsilon \mathrm{I}_{1}$ (extremely underweight) } \\
\hline Boys & 0.4 & -0.4 to 1.3 & -0.3 & -1.5 to 0.9 & 0.3 & $-0.2-0.8$ \\
\hline Girls & 0.1 & -0.5 to 0.7 & -0.8 & -1.7 to 0.1 & 0.2 & $-0.1-0.5$ \\
\hline All & 0.3 & -0.3 to 0.9 & -0.5 & -1.3 to 0.3 & 0.2 & $-0.1-0.6$ \\
\hline \multicolumn{7}{|c|}{ BMI $\varepsilon \mathrm{I}_{2}$ (underweight) } \\
\hline Boys & $1.5^{*}$ & $0.3-2.7$ & $-0.7^{*}$ & -1.7 to 0.3 & $0.7^{*}$ & $0.1-1.3$ \\
\hline Girls & $0.4^{*}$ & -0.1 to 0.9 & $-0.2^{*}$ & -1.2 to 0.8 & $0.2^{*}$ & $0.0-0.5$ \\
\hline All & 1.0 & $0.3-1.6$ & -0.4 & -1.1 to 0.3 & 0.5 & $0.1-0.8$ \\
\hline \multicolumn{7}{|c|}{ BMI $\varepsilon \mathrm{I}_{3}$ (normal weight) } \\
\hline Boys & $-0.3^{*}$ & -0.5 to 0.0 & 0.2 & -0.1 to 0.4 & $-0.1^{*}$ & -0.2 to 0.0 \\
\hline Girls & $-0.6^{*}$ & -0.8 to -0.4 & 0.6 & $0.4-0.8$ & $-0.4^{*}$ & -0.5 to -0.3 \\
\hline All & -0.4 & -0.6 to -0.3 & 0.4 & $0.2-0.5$ & -0.2 & -0.3 to -0.2 \\
\hline \multicolumn{7}{|c|}{ BMI $\varepsilon \mathrm{I}_{4}$ (overweight) } \\
\hline Boys & -1.9 & -2.6 to -1.1 & 0.4 & -0.5 to 1.4 & -0.7 & -1.1 to -0.3 \\
\hline Girls & -1.7 & -2.1 to -1.2 & 1.2 & $0.8-1.5$ & -1.0 & -1.2 to -0.7 \\
\hline All & -1.8 & -2.2 to -1.3 & 0.8 & $0.3-1.3$ & -0.8 & -1.1 to -0.6 \\
\hline \multicolumn{7}{|c|}{ BMI $\varepsilon \mathrm{I}_{5}$ (obese) } \\
\hline Boys & -3.4 & -4.4 to -2.3 & 1.1 & $0.5-1.7$ & -1.5 & -1.8 to -1.2 \\
\hline Girls & -2.9 & -3.8 to -2.0 & 1.6 & $0.9-2.4$ & -1.7 & -2.1 to -1.4 \\
\hline All & -3.1 & -3.8 to -2.5 & 1.4 & $0.8-1.9$ & -1.6 & -1.9 to -1.4 \\
\hline
\end{tabular}

Weight $_{\text {sub }}=$ Self-reported weight height $_{\text {sub }}=$ self-reported height $;$ BMI $_{\text {sub }}=$ BMI calculated from self-reported weight and height.

${ }^{\text {a } D i f f e r e n c e s ~ t h a t ~ a r e ~ s i g n i f i c a n t l y ~ d i f f e r e n t ~ f r o m ~ z e r o ~ a r e ~ h i g h l i g h t e d ~ i n ~ g r e y . ~}$

*Significant differences between boys and girls $(\mathrm{p}<0.05)$. difference was regarded as significant. To determine significant deviations between boys and girls, Student's t-test was performed. The level of significance was set at $\mathrm{p}<0.05$ (two-sided). In linear regression models adjusted for age (as a categorical variable), the effect of measured BMI categories and body image (BI) categories on the difference between selfreported and measured height, weight and BMI was examined, separately for boys and girls.

Participants were classified as underweight, overweight or normal weight on the basis of both the objectively measured BMI and the subjective BMI.

All analyses of KiGGS data were carried out with a weighting factor to correct for population structure deviations between the study sample and the German population (as of December 31,2004) with regard to age (in years), gender, region (East/West) and German/non-German nationality. To allow for the correlation of test persons sampled from the same municipality, the confidence intervals (at the $95 \%$ level) were determined using the SPSS-14 procedure for complex samples.

\section{Probabilities and Conditional Probabilities}

The following terms are used:

Let $\mathrm{P}(\mathrm{BMI} \varepsilon \mathrm{I})$ be the probability that the true BMI of a person belonging to an age- and gender-specific population subgroup of children and adolescents falls within a certain interval I. Then

$$
\begin{aligned}
& \mathrm{P}_{\mathrm{i}}=\mathrm{P}\left(\mathrm{BMI} \varepsilon \mathrm{I}_{\mathrm{i}}\right),(\mathrm{i}=1 \ldots 5) \text { where } \\
& \mathrm{I}_{1}=(-\infty, \mathrm{Pz} 3) \\
& \mathrm{I}_{2}=[\mathrm{Pz} 3, \mathrm{Pz} 10)
\end{aligned}
$$

$$
\begin{aligned}
& \mathrm{I}_{3}=[\text { Pz10, Pz90) } \\
& \mathrm{I}_{4}=[\text { Pz90, Pz97) } \\
& \mathrm{I}_{5}=[\text { Pz97, } \infty),
\end{aligned}
$$

$\mathrm{Pz}_{\mathrm{x}}=\mathrm{x}^{\text {th }}$ percentile of the BMI reference data according to KromeyerHausschild [17].

This means, for example, that a child whose BMI falls within the category $\mathrm{I}_{4}$ is overweight but not obese. Therefore, $\mathrm{P}_{4}$ is the prevalence of overweight without obesity.

By analogy, the probability that the subjective BMI reported by a person belonging to an age- and gender-specific population subgroup falls within an interval $\mathrm{I}$ is

$$
\mathrm{Q}_{\mathrm{i}}=\mathrm{P}\left(\mathrm{BMI}_{\text {sub }} \varepsilon \mathrm{I}_{\mathrm{i}}\right),(\mathrm{i}=1 \ldots 5)
$$

Then by definition of conditional probabilities [21]:

$$
P_{i}=\sum_{j=1}^{5} a_{i j} Q_{j}(i=1 \ldots 5)
$$

with

$$
\mathrm{a}_{\mathrm{ij}}=\mathrm{P}\left(\mathrm{BMI} \varepsilon \mathrm{I} / \mathrm{BMI}_{\mathrm{sub}} \varepsilon \mathrm{I}_{\mathrm{j}}\right)
$$

The correlations between $\mathrm{P}_{\mathrm{i}}$ and $\mathrm{Q}_{\mathrm{i}}$ are examined as a function of age, gender and the adolescents' body image.

The variable $\mathrm{BI}$ assumes values from 1 to 5 :

(3) $\quad-\mathrm{BI}=1$ : test person considers him/herself to be much too thin

- $\mathrm{BI}=2$ : test person considers him/herself to be a bit too thin

- $\mathrm{BI}=3$ : test person considers him/herself to be exactly the right weight 
Table 2. Subjective over- and underestimation of height, weight and BMI by 11- to 17-year-olds as a function of gender and body image

\begin{tabular}{|c|c|c|c|c|c|c|}
\hline & \multicolumn{2}{|c|}{ Weight $_{\text {sub }}$ - weight, $\mathrm{cm}$} & \multicolumn{2}{|c|}{ Height $_{\text {sub }}$ - height, $\mathrm{kg}$} & \multicolumn{2}{|c|}{$\mathrm{BMI}_{\text {sub }}-\mathrm{BMI}, \mathrm{kg} / \mathrm{m}^{2}$} \\
\hline & mean & $95 \%-\mathrm{CI}$ & mean & $95 \%-\mathrm{CI}$ & mean & $95 \%-\mathrm{CI}$ \\
\hline \multicolumn{7}{|c|}{$\mathrm{BI}=1($ much too thin $)$} \\
\hline Boys & 0.0 & -0.9 to 0.9 & -0.2 & -1.1 to 0.8 & 0.1 & -0.3 to 0.4 \\
\hline Girls & 2.2 & -1.9 to 6.2 & -0.5 & -2.0 to 1.0 & 0.9 & -0.5 to 2.3 \\
\hline All & 0.7 & -0.8 to 2.2 & -0.3 & -1.1 to 0.5 & 0.3 & -0.2 to 0.8 \\
\hline \multicolumn{7}{|c|}{$\mathrm{BI}=2($ too thin $)$} \\
\hline Boys & 0.5 & $0.0-1.0$ & 0.4 & -0.1 to 0.8 & 0.1 & -0.1 to 0.3 \\
\hline Girls & -0.2 & -0.6 to 0.3 & -0.1 & -0.8 to 0.7 & -0.1 & -0.2 to 0.1 \\
\hline All & 0.3 & $0.0-0.7$ & 0.2 & -0.1 to 0.6 & 0.1 & -0.1 to 0.2 \\
\hline \multicolumn{7}{|c|}{$\mathrm{BI}=3$ (exactly the right weight) } \\
\hline Boys & -0.3 & -0.6 to 0.0 & -0.1 & -0.5 to 0.3 & $-0.1^{*}$ & -0.2 to 0.1 \\
\hline Girls & -0.5 & -0.7 to -0.3 & 0.3 & -0.1 to 0.6 & $-0.3^{*}$ & -0.4 to -0.1 \\
\hline All & -0.4 & -0.6 to -0.2 & 0.0 & -0.2 to 0.3 & -0.2 & -0.2 to -0.1 \\
\hline \multicolumn{7}{|c|}{$\mathrm{BI}=4$ (too fat $)$} \\
\hline Boys & -1.3 & -1.7 to -1.0 & 0.7 & $0.4-1.1$ & -0.7 & -0.8 to -0.5 \\
\hline Girls & -1.0 & -1.3 to -0.8 & 1.0 & $0.8-1.3$ & -0.7 & -0.8 to -0.6 \\
\hline All & -1.2 & -1.4 to -1.0 & 0.9 & $0.7-1.1$ & -0.7 & -0.8 to -0.6 \\
\hline \multicolumn{7}{|c|}{$\mathrm{BI}=5$ (much too fat $)$} \\
\hline Boys & -1.9 & -2.9 to -0.9 & $-0.6^{*}$ & $-2.1-1.0$ & $-0.4^{*}$ & $-1.0-0.2$ \\
\hline Girls & -1.8 & -2.5 to -1.1 & $1.3^{*}$ & $(0.6-2.0$ & $-1.1^{*}$ & -1.4 to -0.8 \\
\hline All & -1.8 & -2.4 to -1.3 & 0.6 & $-0.2-1.3$ & -0.8 & -1.2 to -0.5 \\
\hline
\end{tabular}

Weight $_{\text {sub }}=$ Self-reported weight; height $\mathrm{sub}_{\text {su }}=$ self-reported height BMI $_{\text {sub }}=$ BMI calculated from self-reported weight and height; $\mathrm{BI}=$ body image.

${ }^{a}$ Differences that are significantly different from zero are highlighted in grey.

*Significant differences between boys and girls $(\mathrm{p}<0.05)$.
- $\mathrm{BI}=4$ : test person considers him/herself to be too fat

- $\mathrm{BI}=5$ : test person considers him/herself to be much too fat.

By analogy to (3) and (4), $R_{i}$ is defined by

$$
R_{i}=P(B I=i),(i=1 \ldots 5)
$$

and by analogy to (5)

$$
\mathrm{P}_{\mathrm{i}}=\sum_{\mathrm{k}=1}^{5} \mathrm{p}_{\mathrm{ik}} \mathrm{R}_{\mathrm{k}}(\mathrm{i}=1 \ldots 5)
$$

where

$$
\mathrm{p}_{\mathrm{ik}}=\mathrm{P}(\mathrm{BMI} \varepsilon \mathrm{I} / \mathrm{BI}=\mathrm{k})
$$

Furthermore, $\mathrm{Q}_{\mathrm{jk}}$ is defined as the probability of the subjective BMI categories $\mathrm{j}$ in the group of people with $\mathrm{BI}=\mathrm{k}$ :

$$
\mathrm{Q}_{\mathrm{jk}}=\mathrm{P}\left(\mathrm{BMI}_{\mathrm{sub}} \varepsilon \mathrm{I} / \mathrm{BI}=\mathrm{k}\right)
$$

Then we can define $\mathrm{a}_{\mathrm{ijk}}$ as the conditional probability that the measured BMI of a person falls within the interval $\mathrm{I}_{\mathrm{i}}$ under the condition that the subjectively assessed BMI falls within the interval $\mathrm{I}_{\mathrm{j}}$ and the body image has value $\mathrm{k}$ :

If

$$
\mathrm{a}_{\mathrm{ijk}}=\mathrm{P}\left(\mathrm{BMI} \varepsilon \mathrm{I} / \mathrm{BMI}_{\mathrm{sub}} \varepsilon \mathrm{I}_{\mathrm{j}}, \mathrm{BI}=\mathrm{k}\right)
$$

from definition (9) follows

$$
\mathrm{p}_{\mathrm{ik}}=\sum_{\mathrm{j}=1}^{5} \mathrm{a}_{\mathrm{ijk}} \mathrm{Q}_{\mathrm{jk}}
$$

and consequently

$$
P_{i}=\sum_{k=1}^{5}\left[\sum_{j=1}^{5} a_{i j k} Q_{j k}\right] R_{k}
$$

\section{Results}

Comparison of Self-Reported and Measured BMI

In the subsample of 1,663 girls and 1,773 boys it was possible to compare the measured data with the subjective statements on height and weight (table 1).

Normal-weight girls and overweight and obese girls and boys underestimated their BMI significantly, whereas underweight boys significantly overestimated their BMI. The tendency to underestimate BMI evident among overweight and obese adolescents increased with 'true' BMI. This underestimation was mostly due to an underestimation of weight: for example, 11- to 17-year-old obese boys and girls underestimated their weight by an average of 3.4 and $2.9 \mathrm{~kg}$, whereas height was overestimated by only 1.1 and $1.6 \mathrm{~cm}$, respectively (table 1 ).

\section{Body Image and Bias of the Subjective BMI}

Adolescents' BI had an impact on the incorrect estimation of their height and weight and therefore their subjective BMI. Girls who considered themselves 'much too fat' or 'too fat' underestimated their BMI; among boys underestimation was only significant for those who considered themselves 'too fat'. Both boys and girls who regarded themselves as much too 
Table 3. Prevalences of defined categories according to measured BMI, estimated BMI and body image, stratified by age and gender

\begin{tabular}{|c|c|c|c|c|c|c|c|c|c|}
\hline \multirow[t]{2}{*}{$\mathrm{i}=$} & \multicolumn{3}{|c|}{ All, \% } & \multicolumn{3}{|c|}{ Boys, \% } & \multicolumn{3}{|c|}{ Girls, \% } \\
\hline & $\mathrm{P}_{\mathrm{i}}$ & $\mathrm{Q}_{\mathrm{i}}$ & $\mathrm{R}_{\mathrm{i}}$ & $P_{i}$ & $\mathrm{Q}_{\mathrm{i}}$ & $\mathrm{R}_{\mathrm{i}}$ & $P_{i}$ & $\mathrm{Q}_{\mathrm{i}}$ & $\mathrm{R}_{\mathrm{i}}$ \\
\hline \multicolumn{10}{|c|}{ 11-13 years } \\
\hline 1 & 2.5 & 3.7 & 2.4 & 2.7 & 4.8 & 3.1 & 2.4 & 2.7 & 1.8 \\
\hline 2 & 5.9 & 7.6 & 10.3 & 6.6 & 7.6 & 11.4 & 5.1 & 7.5 & 9.1 \\
\hline 3 & 72.5 & 71.6 & 44.9 & 72.2 & 70.6 & 49.4 & 72.9 & 72.7 & 40.1 \\
\hline 4 & 11.2 & 10.4 & 34.9 & 10.7 & 10.3 & 30.3 & 11.6 & 10.4 & 39.6 \\
\hline 5 & 7.9 & 6.7 & 7.6 & 7.8 & 6.7 & 5.8 & 8.0 & 6.7 & 9.4 \\
\hline \multicolumn{10}{|c|}{$14-17$ years } \\
\hline 1 & 2.4 & 3.3 & 1.8 & 3.3 & 4.1 & 2.5 & 1.5 & 2.4 & 1.1 \\
\hline 2 & 4.7 & 5.6 & 14.1 & 4.3 & 4.9 & 22.3 & 5.2 & 6.2 & 5.6 \\
\hline 3 & 76.6 & 77.4 & 36.9 & 75.6 & 75.2 & 39.9 & 77.7 & 79.8 & 33.7 \\
\hline 4 & 8.6 & 7.8 & 40.0 & 9.1 & 9.2 & 30.1 & 8.0 & 6.4 & 50.3 \\
\hline 5 & 7.7 & 5.9 & 7.2 & 7.8 & 6.6 & 5.2 & 7.5 & 5.1 & 9.3 \\
\hline \multicolumn{10}{|c|}{ All } \\
\hline 1 & 2.5 & 3.5 & 2.1 & 3.1 & 4.4 & 2.7 & 1.8 & 2.5 & 1.4 \\
\hline 2 & 5.1 & 6.3 & 12.7 & 5.1 & 6.0 & 18.2 & 5.2 & 6.7 & 6.9 \\
\hline 3 & 75.1 & 75.2 & 39.9 & 74.3 & 73.4 & 43.5 & 75.9 & 77.1 & 36.2 \\
\hline 4 & 9.6 & 8.8 & 38.0 & 9.7 & 9.6 & 30.2 & 9.4 & 8.0 & 46.2 \\
\hline 5 & 7.7 & 6.2 & 7.3 & 7.8 & 6.6 & 5.4 & 7.7 & 5.7 & 9.3 \\
\hline
\end{tabular}

$\mathrm{P}_{\mathrm{i}}=$ Measured BMI (i-th category) (i.e., 1 = extremely underweight, 2 = underweight, $3=$ normal weight, 4 = overweight, $5=$ obese); $\mathrm{Q}_{\mathrm{i}}=\mathrm{BMI}$ calculated from self-reported weight and height (i-th category) (i.e., $1=$ extremely underweight, $2=$ underweight, $3=$ normal weight, $4=$ overweight, 5 = obese); $\mathrm{R}_{\mathrm{i}}$ : body image (i-th category) (i.e., $1=$ much too thin, $2=$ a bit too thin, $3=$ exactly the right weight, $4=$ a bit too fat, $5=$ much too fat). thin overestimated their BMI (table 2), but this was not significant.

These deviations resulted in different prevalence estimates for the five weight categories as shown in table 3 .

\section{Misclassification}

The deviations between subjective and objective BMI led to misclassifications within the five weight categories as described in table 4 . The table indicates whether objective BMI classification can be made on the basis of the subjective BMI classification. For each of the five categories of subjective BMI, there are underlying categories of the measured BMI. The coefficients $\mathrm{a}_{\mathrm{ij}}$ from table 4 are the (conditional) probabilities that a survey participant should be in the objective BMI class $i$, given that their subjective statements led to classification in category $\mathrm{j}$ (see definition (6)).

The overall prevalence $P_{i}$ of an objective BMI class I is thus made up of the shares that are 'hidden' in the five subjective BMI categories. Using formula (5), we give two examples derived from table 4 for illustration.

\section{Example 1}

The prevalence of overweight but not obese people and of obese people is calculated as follows (the $a_{i j}$ can be taken from table 4, the $\mathrm{Q}_{\mathrm{i}}$ from table 3):

$$
\begin{aligned}
\mathrm{P}_{4}= & 9.6=0.015 \times 3.5+0 \times 6.3+0.051 \times 75.2+0.575 \times 8.8+ \\
& 0.101 \times 6.2 \\
\mathrm{P}_{5}= & 7.7=0 \times 3.5+0 \times 6.3+0.004 \times 75.2+0.264 \times 8.8+ \\
& 0.824 \times 6.2 .
\end{aligned}
$$

\section{Example 2}

If, additionally, the calculations are stratified by gender, this leads to slightly different probabilities for boys and girls as again can be concluded from the information in tables 3 and 4 .

$$
\mathrm{P}_{4}^{\mathrm{m}}=9.7=0.023 \times 4.4+0 \times 6.0+0.049 \times 73.4+0.533 \times 9.6+
$$

$$
0.134 \times 6.6
$$

the prevalence of overweight, but not obese male adolescents,

$$
\mathrm{P}_{4}^{\mathrm{f}}=9.4=0 \times 2.5+0 \times 6.7+0.052 \times 77.1+0.629 \times 8.0+
$$
$0.062 \times 5.7$

the prevalence of overweight, but not obese female adolescents,

$$
\mathrm{P}_{5}^{\mathrm{m}}=7.8=0 \times 4.4+0 \times 6.0+0.002 \times 73.4+0.265 \times 9.6+
$$

$$
0.768 \times 6.6
$$

the prevalence of obese male adolescents,

$$
\mathrm{P}_{5}^{\mathrm{f}}=7.7=0 \times 2.5+0 \times 6.7+0.007 \times 77.1+0.263 \times 8.0+
$$$$
0.891 \times 5.7
$$

the prevalence of obese male adolescents.

\section{Correction Procedure I}

If the conditional probabilities $\mathrm{a}_{\mathrm{ij}}$ between subjective and objective weight classifications found on the basis of a represen- 


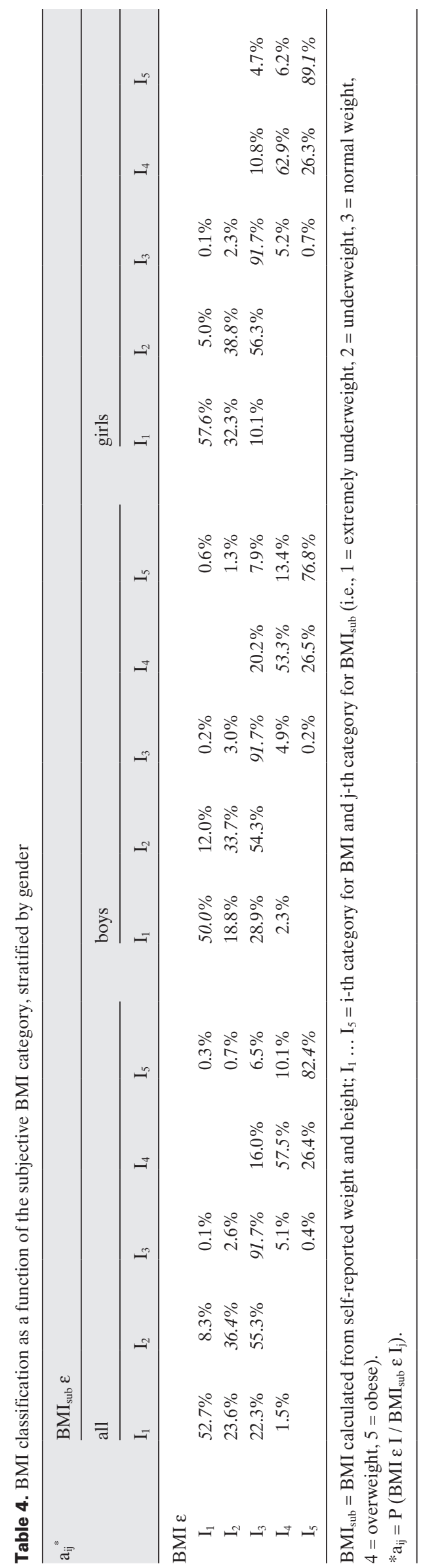

tative survey can be generalized, this would allow - for studies $S$ based only on subjective statements - an estimation of the (unknown) prevalence of overweight, normal weight and underweight that corrects (in a gender-and age-specific manner) the bias introduced by self-reporting BMI.

Replacing in formula (5) the $\mathrm{Q}_{j}$ of the validation study (here the KiGGS study) by the subjective BMI categories $Q_{j}^{s}$ of a second study $\mathrm{S}$ we obtain

$$
\hat{P}_{j}=\sum_{j=1}^{5} a_{i j} Q_{j}^{S}(i=1 \ldots . .5)
$$

This estimation can be applied to every study $\mathrm{S}$ where the conditional probabilities $\mathrm{a}_{\mathrm{ij}} \mathrm{V}$ are known from a parallel representative validation study V.

\section{Misclassification, Modified by Body Image}

As the data from the KiGGS study show, the relationships between subjective and objective BMI classifications again differ by self-assessed BI group.

Table 5 shows the conditional probabilities of BMI classification as a function of $\mathrm{BMI}_{\text {sub }}$, subjective $\mathrm{BI}$ and gender. Because of the sample size, here only three categories of BI were used. We combined BI category 1 with 2 and category 4 with 5 such that

$$
\begin{aligned}
& \overline{\mathrm{BI}}=1 \text { if } \mathrm{BI}=1 \text { or } \mathrm{BI}=2 \\
& \overline{\mathrm{BI}}=2 \text { if } \mathrm{BI}=3 \\
& \overline{\mathrm{BI}}=3 \text { if } \mathrm{BI}=4 \text { or } \mathrm{BI}=5 .
\end{aligned}
$$

Then

$$
\begin{aligned}
\mathrm{r} 1 & =\mathrm{P}(\overline{\mathrm{BI}}=1)=\mathrm{R}_{1}+\mathrm{R}_{2}=0.148 \\
\mathrm{r} 2 & =\mathrm{P}(\overline{\mathrm{BI}}=2)=\mathrm{R}_{3}=0.399 \\
\mathrm{r} 3 & =\mathrm{P}(\overline{\mathrm{BI}}=3)=\mathrm{R}_{4}+\mathrm{R}_{5}=0.453 \text { (see definition (7) } \\
& \quad \text { and table } 3)
\end{aligned}
$$

According to this, the accuracy of the subjective BMI classification depends on the test person's BI. This makes it possible to determine the objective BMI class more exactly by incorporating information on BI with the subjective BMI category (formula 13).

\section{Example 3}

The following examples illustrate the use of coefficients $a_{i j k}$ and $\mathrm{Q}_{\mathrm{jk}}$ from table 5 in formula (13) to calculate the prevalence of overweight and obesity.

$$
\begin{aligned}
\mathrm{P}_{4}= & 9.6=\mathbf{0 . 1 4 8} \times(0 \times 14.4+0 \times 18.7+0 \times 65.3+0.269 \times 1.1+0 \\
& \times 0.5)+\mathbf{0 . 3 9 9} \times(0 \times 3.0+0 \times 7.6+0.015 \times 85.9+0.416 \times \\
& 2.8+0.186 \times 0.7)+\mathbf{0 . 4 5 3} \times(0.38 \times 0.3+0 \times 1.2+0.105 \times \\
& 69.0+0.605 \times 16.6+0.098 \times 12.8)
\end{aligned}
$$

the prevalence of overweight but not obese subjects, $\mathrm{P}_{5}=7.7=\mathbf{0 . 1 4 8} \times(0 \times 14.4+0 \times 18.7+0 \times 65.3+0.349 \times 1.1+0$ $\times 0.5)+\mathbf{0 . 3 9 9} \times(0 \times 3.0+0 \times 7.6+0 \times 85.9+0.061 \times 2.8+$ 


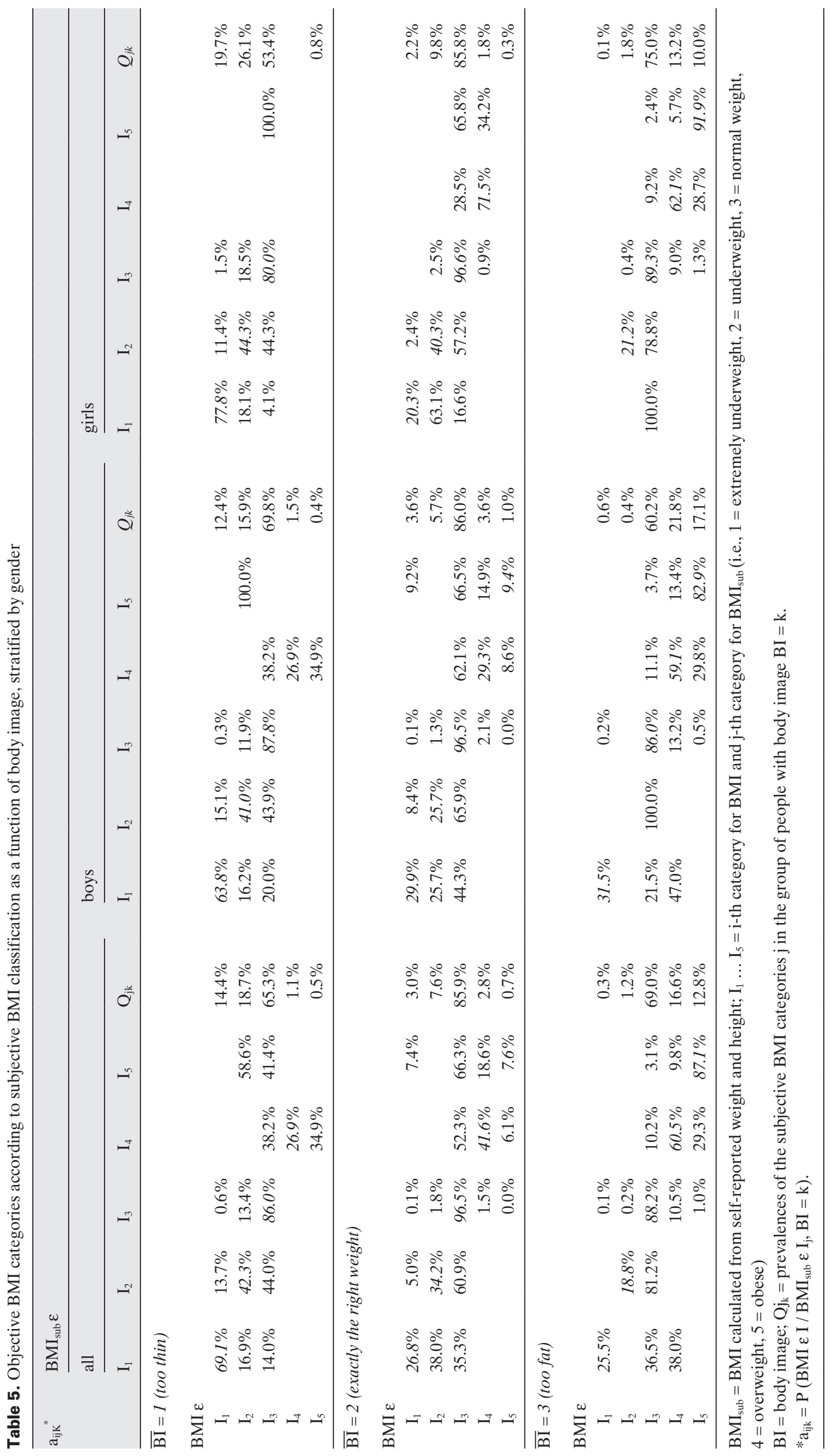


$0.076 \times 0.7)+\mathbf{0 . 4 5 3} \times(0 \times 0.3+0 \times 1.2+0.01 \times 69.0+0.293$

$\times 16.6+0.871 \times 12.8)$

the prevalence of obese subjects.

These prevalences again differ by gender.

\section{Example 4}

The prevalences for male and female adolescents are calculated according to tables 3 and 5:

$\mathrm{P}_{4}^{\mathrm{m}}=9.7=\mathbf{0 . 2 0 9} \times(0 \times 12.4+0 \times 15.9+0 \times 69.8+0.269 \times 1.5+0$ $\times 0.4)+\mathbf{0 . 4 3 5} \times(0 \times 3.6+0 \times 5.7+0.021 \times 86.0+0,293 \times$ $3.6+0.146 \times 1.0)+\mathbf{0 . 3 5 6} \times(0.47 \times 0.6+0 \times 0.4+0.132 \times$ $60.2+0.591 \times 21.8+0.134 \times 17.1)$

$\mathrm{P}_{4}^{\mathrm{f}}=9.4=\mathbf{0 . 0 8 3} \times(0 \times 19.7+0 \times 26.1+0 \times 53.4+0 \times 0+0 \times$ $0.8)+\mathbf{0 . 3 6 2} \times(0 \times 2.2+0 \times 9.8+0.009 \times 85.8+0.715 \times 1.8$ $+0.342 \times 0.3)+\mathbf{0 . 5 5 5} \times(0 \times 0.1+0 \times 1.8+0.09 \times 75.0+$ $0.621 \times 13.2+0.057 \times 10.0)$

$\mathrm{P}_{5}^{\mathrm{m}}=7.8=\mathbf{0 . 2 0 9} \times(0 \times 12.4+0 \times 15.9+0 \times 69.8+0.349 \times 1.5+$ $0 \times 0.4)+\mathbf{0 . 4 3 5} \times(0 \times 3.6+0 \times 5.7+0 \times 86.0+0.086 \times 3.6$ $+0.094 \times 1.0)+\mathbf{0 . 3 5 6} \times(0 \times 0.6+0 \times 0.4+0.005 \times 60.2+$ $0.298 \times 21.8+0.829 \times 17.1)$

$\mathrm{P}_{5}^{\mathrm{f}}=7.7=\mathbf{0 . 0 8 3} \times(0 \times 19.7+0 \times 26.1+0 \times 53.4+0 \times 0+0 \times$ $0.8)+\mathbf{0 . 3 6 2} \times(0 \times 2.2+0 \times 9.8+0 \times 85.8+0 \times 1.8+0 \times$ $0.3)+\mathbf{0 . 5 5 5} \times(0 \times 0.1+0 \times 1.8+0.013 \times 75.0+0.287 \times$ $13.2+0.919 \times 10.0)$

\section{Correction Procedure II}

Information on subjective BI could improve the accuracy of prevalence estimates of overweight and obesity in study $\mathrm{S}$ without objective height and weight measurements. Estimation by equation (14) can be improved by knowledge of participants' subjective BI.

By using the conditional probabilities $\mathrm{a}_{\mathrm{ijk}}$ (see equation (11)) of a validation study that assesses information about the BI of participants in addition to the measured and subjectively assessed BMI, the bias introduced by the subjective BMI can be reduced.

Replacing $\mathrm{Q}_{\mathrm{jk}}$ and $\mathrm{R}_{\mathrm{k}}$ in formula (13) by the corresponding prevalences $Q_{j k}^{s}$ and $R_{k}^{s}$ from the study $S$ the resulting correction formula is

$$
\mathrm{P}_{\mathrm{i}}=\sum_{\mathrm{k}=1}^{5}\left[\sum_{\mathrm{j}=1}^{5} \mathrm{a}_{\mathrm{ijk}} \mathrm{Q}_{\mathrm{jk}}^{\mathrm{S}}\right] \mathrm{R}_{\mathrm{k}}^{\mathrm{S}}(\mathrm{in}=1 \ldots . .5)
$$

where

$$
\mathrm{a}_{\mathrm{ijk}}=\mathrm{P}\left(\mathrm{BMI} \varepsilon \mathrm{I} / \mathrm{BMI}_{\mathrm{sub}} \varepsilon \mathrm{I}_{\mathrm{j}}, \mathrm{BI}=\mathrm{k}\right)
$$

is determined by a validation study, $\mathrm{R}_{\mathrm{k}}^{\mathrm{s}}$ is the prevalence of the body image category $\mathrm{k}$ in the study $\mathrm{S}$, and

$$
\mathrm{Q}_{\mathrm{jk}}^{\mathrm{s}}=\mathrm{P}\left(\mathrm{BMI}_{\mathrm{sub}} \varepsilon \mathrm{I}_{\mathrm{j}} / \mathrm{BI}=\mathrm{k}\right)
$$

are the prevalences of the subjective BMI categories $\mathrm{j}$ in the group of people with $\mathrm{BI}=\mathrm{k}$ in the study $\mathrm{S}$.
Equation (16) is valid for any study that only has information on subjective BI and subjective BMI as long as a parallel validation study $\mathrm{V}$ is conducted to estimate the conditional distribution of objective BMI according to subjective BMI for different boBI groups. It has to be mentioned that even the coefficients $\mathrm{a}_{\mathrm{ijk}}$ may differ by time, by gender and by cultural background of the participants. Therefore, we used $\mathrm{a}_{\mathrm{ijk}} \mathrm{v}$ to indicate the results of a representative, up-to-date validation study V.

\section{Discussion}

For practical and economic reasons, height and weight are frequently ascertained only by self-report in epidemiological studies. The extent to which subjective estimation of BMI leads to a bias in estimates of the prevalence of overweight and obesity has been examined in specialist literature. A review article [9] examined mistakes in the prevalence estimates of overweight and obesity in adolescents presented in 11 studies from 11 countries. The review concluded that the prevalence of overweight and obesity among adolescents is grossly underestimated when subjective data are used. Furthermore, misclassification is more frequent among people who are truly overweight or obese as well as among girls. The authors recommended that the level of bias in subgroups of children and adolescents be examined more closely.

Among 418 pupils in Wales (participating in the WHO HBSC study), measurements of height and weight were carried out parallel to collecting data from questionnaires [22]. It was noted that, in order to assess the public health relevance of overweight and obesity, measured data must be considered to assess the extent of misclassification by subjective data. A study of Greek schoolchildren came to the same conclusion [23]. Regular national validation studies are called for in order to be able to assess the validity of subjective assessments.

Precisely this has been implemented with the KiGGS study in Germany. Asking 11- to 17-year-old KiGGS participants their height and weight and measuring it at the same time opens up the possibility to determine bias more accurately as a function of various influence factors.

Normal-weight adolescents in the KiGGS study gave a realistic assessment of their height and weight and therefore also of their BMI. Overweight participants tended to underestimate their weight. This led to a misclassification of their BMI and consequently to an underestimation of the prevalence of overweight and obesity. This did not depend on education or social status [24]. These results are highly valuable in the international context because they are based on a representative study with a large sample size.

This paper shows that, for studies $\mathrm{S}$ of a special age group of adolescents that only assess self-reported weight and height and therefore only obtain subjective BMI, there is a correction procedure for the biased prevalence estimations of overweight and 
obesity. The only condition is that a validation study $\mathrm{V}$ exists, which is representative for the same age group of adolescents as the study $\mathrm{S}$ and can be used to calculate the conditional distributions of objective BMI according to subjective BMI. The corresponding correction procedure is described in equation (14).

Furthermore, the KiGGS data have shown that the deviations between subjective and measured BMI differ not only between the sexes but also between groups with different subjective BIs (similar results are found in [8] and [9]).

A large percentage of both girls and boys in the KiGGS study whose BMI is actually normal consider themselves too fat. Although this occurs more frequently among girls than boys, it is encountered in both sexes. The reverse is true among obese participants. Here, girls are more realistic than boys. $60.6 \%$ of obese girls, but only $32.2 \%$ - i.e. under one third - of boys recognize that they are 'much too fat'. Most obese participants considered themselves 'a bit too fat'. When it comes to subjective statements on height and weight, false self-perception of BI influences the bias in the opposite direction: adolescents who consider themselves much too fat report their weight as being lower than it really is, and young people who consider themselves too thin correspondingly 'adjust' their weight upwards. Adolescents who consider themselves 'exactly right' also provide more realistic information on their height and weight than other groups.

In this paper a correction procedure is proposed for prevalence estimation of overweight and obesity obtained through subjective BMI assessments. The procedure calls for simultaneously recording both the subjective and the objective BMI and asking for the subjective BI. For example this correction procedure can be applied to the German HBSC study [20] where adolescents were asked their BI as well as their height and weight. In this case the German KiGGS study will serve as the validation study for correcting the bias in the subjective BMI. The KiGGS study, as a representative study of German adolescents aged between 11 and 17 years old, overlaps the age groups of the HBSC study and was carried out in the same time period. Therefore, the KiGGS study can provide the coefficients $\mathrm{a}_{\mathrm{ijk}}$ in equation (16). In a future part II of this paper, the corrected estimates of the prevalence of overweight and obese pupils in Germany will be published.

\section{Conclusions}

The correction procedure described in this paper can also be used in the international context if a representative study exists that collected information about measured and self-reported BMI as well as self-perceived BI. With the data from this study, the dependence of the bias in the self-reported BMI on the self-perceived BI can be assessed. Applying the properties of conditional probabilities, the correction formula (16) can be applied to any epidemiological study S that collected information only on self-reported BMI and self-perceived BI at approximately the same time. Although the coefficients $\mathrm{a}_{\mathrm{ijk}}$ will differ by time, age groups, gender and nationality, the general principle remains valid. Considering the BI of study subjects can improve prevalence estimates of overweight, obesity and other BMI categories.

\section{Acknowledgements}

The KiGGS study was funded by the German Federal Ministry of Health, the Ministry of Education and Research, and the Robert Koch Institute.

The authors are indebted to all those who participated in this study and their parents for filling in the questionnaires and answering our questions. We thank the mayors and authorities of all 167 study communities for their endorsement and help. This complex study could not have been realized without the strong commitment of the study teams and so many more colleagues in the Robert Koch Institute.

Special thanks to Sebastian Ellert for his contribution to editing the equations in this manuscript and to our colleague Benjamin Barnes for proofreading the manuscript.

\section{Disclosure}

The authors declare that they have no competing interests.

\section{References}

1 Hill A, Roberts J: Body mass index: a comparison between self-reported and measured height and weight. J Public Health Med 1998;20:206-210.

2 Flood V, Webb K, Lazarus R, Pang G: Use of selfreport to monitor overweight and obesity in populations: some issues for consideration. Aust $\mathrm{N} \mathrm{Z} \mathrm{J}$ Public Health 2000;24:96-99.

3 Nyholm M, Gullberg B, Merlo J, LundqvistPersson C, Råstam L, Lindblad U: The validity of obesity based on self-reported weight and height: Implications for population studies. Obesity (Silver Spring) 2007;15:197-208.

4 Dauphinot V, Wolff H, Naudin F, Guéguen R, Sermet C, Gaspoz JM: New obesity body mass index threshold for self-reported data. J Epidemiol Community Health 2009;63:128-132.
5 Roberts RJ: Can self-reported data accurately describe the prevalence of overweight? Public Health 1995;109:275-284.

6 Alvarez-Torices JC, Franch-Nadal J, AlvarezGuisasola F, Hernandez-Mejia R, Cueto-Espinar A: Self-reported height and weight and prevalence of obesity. Study in a Spanish population. Int J Obes Relat Metab Disord 1993;17:663-667.

7 Bolton-Smith C, Woodward M, Tunstall-Pedoe H, Morrison C: Accuracy of the estimated prevalence of obesity from self reported height and weight in an adult Scottish population. J Epidemiol Community Health 2000;54:143-148.
8 Madrigal H, Sánchez-Villegas A, Martínez-González MA, Kearney J, Gibney MJ, Irala J, Martínez JA: Underestimation of body mass index through perceived body image as compared to self-reported body mass index in the European Union. Public Health 2000;114:468-473.

9 Sherry B, Jefferds ME, Grummer-Strawn LM: Accuracy of adolescent self-report of height and weight in assessing overweight status: a literature review. Arch Pediatr Adolesc Med 2007;161:1154-1161.

10 Strauss RS: Comparison of measured and self-reported weight and height in a cross-sectional sample of young adolescents. Int J Obes Relat Metab Disord 1999;23:904-908.

11 Goodman E, Hinden BR, Khandelwal S: Accuracy of teen and parental reports of obesity and body mass index. Pediatrics 2000;106:52-58. 
12 Giacchi M, Mattei R, Rossi S: Correction of the self-reported BMI in a teenage population. Int $\mathrm{J}$ Obes Relat Metab Disord 1998;22:673-677.

13 Rasmussen F, Eriksson M, Nordquist T: Bias in height and weight reported by Swedish adolescents and relations to body dissatisfaction: the COMPASS study. Eur J Clin Nutr 2007;61:870-876.

14 Jansen W, van de Looij-Jansen PM, Ferreira I, de Wilde EJ, Brug J. Differences in measured and self-reported height and weight in Dutch adolescents. Ann Nutr Metab 2006;50:339-346.

15 Mikolajczyk RT, Maxwell AE, Ansari WE, Stock C, Petkeviciene J, Guillen-Grima F: Relationship between perceived body weight and body weight and body mass index based on self-reported height and weight among university students: a crosssectional study in seven European contries. BMC Public Health 2010;10:40.

16 Kurth BM, Kamtsiuris P, Hölling H, Schlaud M, Dölle R, Ellert U, Kahl H, Knopf H, Lange M, Mensink GB, Neuhauser H, Schaffrath Rosario AS, Scheidt-Nave C, Schenk L, Schlack R, Stolzenberg H, Thamm M, Thierfelder W, Wolf U: The challenge of comprehensively mapping children's health in a nation-wide health survey: design of the German KiGGS-Study. BMC Public Health 2008;8:196.
20 Richter M, Hurrelmann K, Klocke A, Melzer W, Ravens-Sieberer U (Hrsg): Gesundheit, Ungleichheit und jugendliche Lebenswelten. Ergebnisse der zweiten internationalen Vergleichsstudie im Auftrag der Weltgesundheitsorganisation WHO Weinheim, Juventa, 2008.

21 Feller W (eds): An Introduction to Probability Theory and Its Applications, vol. I. New York, Wiley, 1968. ziehung verschiedener deutscher Stichproben. Monatsschr Kinderheilkd 2001;149:807-818.

18 Kurth BM, Schaffrath Rosario A: The prevalence of overweight and obese children and adolescents living in Germany. Results of the German Health Interview and Examination Survey for Children and Adolescents (KiGGS). Bundesgesundheitsbl Gesundheitsforsch Gesundheitsschutz 2007;50: 736-743.

19 Currie C, Samdal O, Boyce W and Smith R (eds): Health Behaviour in School-Aged Children: a WHO Cross-National Study (HBSC), Research Protocol for the 2001/2002 Survey. Child and Adolescent Health Research Unit (CAHRU), University of Edinburgh, 2001.
22 Elgar FJ, Roberts C, Tudor-Smith C, Moore L: Validity of self-reported height and weight and predictors of bias in adolescents. J Adolesc Health 2005;37:371-375.

23 Tokmakidis SP, Christodoulos AD, Mantzouranis NI: Validity of self-reported anthropometric values used to assess body mass index and estimate obesity in Greek school children. J Adolesc Health 2007; 40:305-310.

24 Kurth BM, Ellert U: Perceived or true obesity: which causes more suffering in adolescents? Findings of the German Health Interview and Examination Survey for Children and Adolescents (KiGGS). Dtsch Arztebl Int 2008;105:406-412. 